\title{
Qatari Intersections with Global Genetics Research and Discourse
}

\author{
Disclaimer: \\ This publication was made possible by two NPRP grant \#s [NPRP 5-22I-3-064; NPRP 4- \\ 1204-5- 177] from the Qatar National Research Fund (a member of Qatar Foundation). The \\ statements made herein are solely the responsibility of the author.
}

\section{Acknowledgements:}

I would like to thank my collaborators and Co-LPIs: Dr. Fouad Al-Shaban, Qatar Biomedical Research Institute, Qatar; and Dr. Stella Major, Weill-Cornell Medicine, Qatar. I would also like to thank my research specialists: Nadia Omar, Mona Mohsen and Tasneem Al-Raisi for their dedicated work on the projects.

Ethics approval for these studies was granted from relevant Qatari institutions: Shafallah Medical Genetics Centre; Hamad Medical Corporation; and Weill Cornell Medicine- Qatar and University College London. I refer to all research participants using pseudonyms.

\begin{abstract}
Genetic discourses have taken a predominant role in approaches to combating a number of conditions that affect Qataris. This paper is derived from an exploration of Qatari encounters with globalizing discourses of genetics, particularly as they relate to notions of risk. It explores Qataris negotiations of global interactions and influences, including the discourses around genetic risk and cousin marriage. It suggests that family marriage can be seen as one of the main platforms of resistance and a means for modern, cosmopolitan and tradition to be negotiated.
\end{abstract}

\section{Introduction}

Like other populations in the Middle East, Qataris have increased susceptibility to some diseases, including: diabetes, cardiovascular disease, obesity, and some neurological disorders. Genetic discourses have predominated in Qatari approaches to combating these conditions. Discussions around genetics also prevail because of the high frequency of consanguineous marriages in the country and concerns about its genetic effects. Rates of genetic disorders and birth defects are relatively high given the small population size. Autosomal recessive disorders are increased due to consanguinity, but also common, multifactorial disorders such as diabetes mellitus type 2, obesity, psychosis, and congenital malformations are seen in excess (Bener and Alali 2006; Bener et al., 2007). There are particular concerns about high rates of sickle-cell aneamia; thalassemia; homosystinuria; and mental retardation. Qatar provides an opportunity to explore issues around discourses of genetic risk where despite the global spread of biomedicine, a culture of transnational research, and a commitment to modernization we witness a continuing dedication to the practice of consanguineous marriage. The paper investigates the way medical technologies and research; particularly those that focus on genetics are the focus of the Qatari state's positioning as a global political and economic presence. The research on which this paper is based contributes to the literature on modernity and globalization by focusing on the Qatari context where rapid social change and globalizing forces have been met by negotiations and, in particular, containment at the individual, group and state level. The paper thus contributes to the literature on the impacts of discourses of genetic risk in consanguineous marriage in diverse global settings (Shaw and Raz 2015). 
This paper is derived from an exploration of Qatari encounters with globalizing discourses of genetics, particularly as they relate to notions of risk. I draw on my experience of living in and conducting research in Qatar (20I0-20I6). During this period I conducted two research projects: one an investigation into miscarriage and the other a general investigation into public understandings of genetics and notions of risk, disability and illness. During the course of my research interlocutors commented on issues around inheritance, genetics, risk, illness and health. In addition, the paper is based on analysis of Qatari medical research and government documents. I situate this paper's findings amongst social science research focusing on how new medical technologies and knowledge, including those involving genetics, are accommodated, contained and resisted within local moral landscapes (Inhorn 2009). The analysis and interpretation of research findings is informed by current anthropological knowledge and analytical approaches to the topic of genetics in the Middle East region. A variety of scholars (i.e. Panter-Brick 1991, Raz 2005, Beaudevin 2013, Parkhurst 2014) explore genetics in the Middle East. Raz (2005) explores what happens when this "newly discovered scientific notion of 'fate' encounters its traditional and religious conception" (xv) amongst the Negev Bedouin community in Israel. Beaudevin's (20I3) research on inherited blood disorders in Oman reveals, "the way increased biomedical knowledge and the outcomes of its applications can affect a society" (p. I85). Panter-Brick's (199I) research in Saudi Arabia shows the profound impact that knowledge of genetics has on family relationships. Scholarly works such as these have shed light on the way encounters with genetics alter social life and understandings in fundamental ways.

The paper explores Qatari negotiations of biomedical genetic knowledge, particularly in light of marriage practices and ideas about reproduction. The paper first presents material on the medical and research platform in Qatar, particularly the central role genomics and genetic medicine hold within the development agenda. In particular, I argue that a focus on genetic discourses and genetic research underpins the Qatari quest for modernity. The paper explores the way in which genetic medicine and research is at the forefront of the Qatari state's mission as a "modern" nation and a world leader in research, education and international politics. This impetus can be at odds, however, with the way that Qataris themselves understand and incorporate genetic knowledge into their lives. Thus, the second part of the paper considers local Qatari knowledge systems and explores the tensions and negotiations in their intersections with modernizing genetic discourses. I show that Qataris meet such discourses with processes of containment, in a balancing of the traditional and the modern. With regard to the dominant discourse around genetic risk and cousin marriage, the increase in family marriage can be seen as one of the main platforms of resistance and negotiation.

\section{Methods}

This paper is based on several years of research on/ in Qatar including two ethnographic research projects. The paper primarily draws on fieldwork conducted over 12 months (2012-2013) during which accounts were collected about notions of health risk and, particularly, genetic risk (for a full description of methods see XXX 20I5). Interviews were conducted with 45 families whose children were pupils at a school for special needs. Because of the presence of the medical genetics centre at the same facility, families of students were at the interface of public understandings of genetics. Families had been exposed to genetics through general discussions by staff or more directly exposed through genetic testing. Interviews included collecting basic demographic information about the family, marriage patterns, education and occupation. General questions about notions of health, illness and risk were asked. Questions probed notions of inheritance and genetics, i.e. 'who provides the genetic material to a child' as well as questions to explore how traits (i.e. intelligence, physical traits, and so on) were passed down through generations. Qualitative, flexible, and open-ended methods were used to focus on the perceptions, experiences and views of 
interlocutors. Professionals involved in the creation of genetic knowledge and those at the interface between the public and genetic discourse were interviewed including: social workers, geneticists, and those involved in medical screening programmes. Additional information about public understandings of genetics is provided by ongoing exploration of documents, including media and government policy documents as well as data derived from 18 months (2013-2015) ethnographic research on pregnancy and miscarriage (for description of methods see $X X$ in press). The latter involved interviews with 60 women and 55 secondary participants (family members, health care providers, religious leaders etc), whose discussions about conception and inheritance inform this paper. Analysis of the qualitative data sets generated by the research was through a process of thematic coding and analysis that make use of a grounded theory approach (Strauss and Corbin 1990). Regular reading and re-reading of interviews and field observations identified themes for exploration in subsequent interviews. Analysis for this paper involved identifying themes related to the topics of risk, genetic risk, illness causality and inheritance. As themes emerged, data were re-analysed to develop and refine the findings. Several over-arching themes were identified, providing a framework through which I present and contextualize the findings.

\section{Qatar: modernity}

Visitors to Doha often express surprise at its state of the art appearance; its skyline dominated by high-rise modern buildings raised from the ground at an astonishing rate. The city is continuously changing, growing, and evolving: one is overwhelmed by sounds of around the clock construction work and left confused by suddenly altered roads. Photographs of 1980s Doha show a desert with a few low buildings: surrounded by desert sand, the pyramidic Sheraton Hotel stands out as the only building taller than a few stories. Today, the hotel is dwarfed by the modern steel and glass skyscrapers, which surround it. The city itself is a symbol of Qatar's rapid social and economic development, representing the county's ability to change itself and its surrounding environment at a rapid rate fuelled by its high-income economy. Qatar is characterized by the striking modernity of its urban built space and its pace of social change.

A small country occupying the Qatar Peninsula on the northeastern coast of the Arabian Peninsula, Qatar's recent social and economic changes have occurred as the result of the discovery of natural gas and oil in 1940. This discovery turned Qatar from a largely Bedouin society that depended on fishing and pearl fishing to the richest country in the world. In 2013 its population was 1.8 million people, with Qatari citizens representing a minority at only 278000 people. The rest of the population is comprised of migrant workers from all over the world. A British protectorate in the early $20^{\text {th }}$ century, the country gained independence in 197I. An absolute monarchy headed by Emir Sheikh Tamim bin Hamad Al Thani, it is a conservative country with most Qataris adhering to strict Salafi interpretation of Islam. Sharia law is the main source of legislation in the country. Despite its conservatism, the country has endeavoured to be an influential link between the Arab world and the west and has worked to develop a reputation as a progressive Arab nation in terms of education, research, as well as economically and politically. The home of Al Jazeera Media Network, Qatar positions itself as an influential player in the Arab world and supported several rebel groups during the Arab spring. The country has had a high profile of late due to these issues, its investment in a number of high profile holdings (i.e. in the UK: Harrods, The Shard) but also because it is to host the Fifa 2022 World Cup and has been embroiled in the accusations of corruption that has accompanied its bid. Further damaging Qatar's reputation has been criticism of its treatment of migrant workers, which has gained a great deal of media attention in recent years.

Qatar is positioning itself as a world leader in research and medical technology: "In striving toward this vision, Qatar will distinguish itself within the region and world as a cosmopolitan nation that embraces scholarly excellence, innovation, creativity, inclusiveness and merit."(http://www.qnrf.org/en-us/About-Us/Vision-Mission). But what 
does cosmopolitan mean in this context? The Oxford dictionary suggests a number of meanings: familiar and at ease with many different cultures, including people from many different cultures, exciting and glamorous character associated with a mix of cultures. One can look to a number of recent initiatives to better understand what cosmopolitanism means in this context, such as "Education City," a I4 square kilometer area in Doha, which houses branch campuses from a number of leading American and one (UCL) British university. An initiative of the Qatar Foundation (QF), it is conceived as a forum for exchange, where universities collaborate with businesses and institutions in both the public and private sector. It is seen as a cosmopolitan space, where Qataris, other Gulf Arabs, and students from other nations mix and are taught by foreign (predominantly American and European) professionals. The aim of Qatar's focus on creating world class education for Qataris at Education City predominantly is built upon a notion of education as a "means of creating marketable, international skill; education is focused on connecting Qatar to the outside world" (Fromherz 2012:10). Education City stands at the intersection of two sets of interests: being at one with the globalised world while aspiring to stand apart from it, as Kane (2013) describes in her research into medical education. The Qatari leadership did not recruit from the pool of established regional medical schools, but deliberately chose to import one from the U.S, notes Kane (2013). Although a regional medical college would "offer a professional training more in keeping with core Qatari values and culture, the US programme was perceived to be superior both in terms of its quality of training and its capacity to develop a domestic research platform which could communicate at an international level" (Kane 2013: I0I). Diverging from the aims of other pursuants of globalised and globalising education, the Qatari state is:

Not aiming to produce neoliberal subjects trained for employment in global knowledge-driven economies. Rather, citizens are being presented with opportunities to equip themselves with specific skills in order to participate in the development of a domestic knowledge-based economy (Kane 20I3:I0I).

To this end, a number of measures are activated to ensure the maintenance of Qatari values and to nourish a local set of principles of development. Concerned about their dependence on foreign labour and outside expertise, the Qatari state has introduced a number of governmental initiatives devised to increase the number of Qatari citizens employed in public and private sectors. These initiatives are part of the so-called "Qatarisation" of the nation, a focus of the Qatar National Vision (QNV) 2030. This development plan was launched in 2008 by His Highness Sheikh Hamad bin Khalifa Al Thani to provide a "clear roadmap of Qatar's future" and to "transform Qatar into an advanced society capable of achieving sustainable development" (http://www.gsdp.gov.qa/portal/page/portal/gsdp_en/qatar_national_vision).

The structure of Education City is indicative of the general dependence on the outside, which can be seen throughout Qatar economic, social and political arenas: 90 per cent of Qatar's food comes from overseas. This dependence has become a preoccupation of Qatar's political elite (Fromherz 2012:II). Thus, the model is bringing from the outside to create Qatari citizens and improve Qatar, but such imports are contained and controlled. As Douglas (1966) has suggested, when boundaries between categories are unclear, contradictory or broken down, the resulting category confusion is seen as polluting and potentially dangerous, requiring containment strategies. Containment is seen throughout Qatari policy and approaches to outside forces, which focuses on limiting such forces seen polluting or corrupting Islamic and Qatari values: such as the tight restriction on the sale and use of alcohol; restrictions on the behavior and movements of certain migrant workers and, of course, the policy of Qatarisation itself. The state restricts the ideological influence of others. 
Commentators have suggested that the focus of education in Qatar is on connecting with the outside world rather than inward criticism or reform it is, "not on the issues of governance and society within Qatar itself" (Fromherz 2012:10). The main instrument of containment is through constant emphasis on tradition. Qatar positions itself as innovative, modern and open to learning from other cultures. However, the emphasis is on retaining Qatari customs and authenticity as well and benefitting Qataris specifically. Gulf regimes, such as Qatar, actively seek to create, "invented traditions" in order to maintain and deepen their legitimacy and relevance, with such "heritage engineering" represented by the emphasis on cultural activities such as folkloric customs, national dress, as well as the passion for museums and a renewed attention to suqs, as in Doha's reconstructed and reimagined Suq Waqif (Cooke 20l4). In this context the Qatari notion of cosmopolitan seems to mean welcoming in, making use of, and learning from outside influences, but only whilst retaining a strong sense of continuing Qatari identity and culture.

\section{Qatari Medical Research landscape}

Qatar has pledged to spend $2.8 \%$ of its GDP on research (of 211.82 USD billion estimated) with the majority of these funds being managed by the QF, which establishes the country's research strategy, heavily influencing where funding is channeled. The Vision of QF is to enhance the education of its citizens and training of its workforce and fostering improvements in health, wellbeing, environment of "its own people and those of the region". The QF launched Qatar National Research Fund (QNRF) in 2006 as part of its ongoing commitment to establish a knowledge-based economy. Applications must emphasise how the research will directly benefit Qatar, this being key criterion for evaluation. In 2012 Qatar presented its first National Research Strategy (QNRS), whose mission is: "to build and maintain a competitive and diversified economy; improve the health and social wellbeing of Qatar's population; and support Qatar's distinctive culture and the security of its people" (http://www.qnrf.org/en-us/About-Us/QNRS). Included in the QNRS is the development of "plans to tackle Cancer, Diabetes \& develop personalised medicine" and to develop a "dedicated research program focused on the understanding of the genetic causes of diseases and conditions in Qatar." Indeed, considerable state funds have been channeled towards understanding the country's high rates of diabetes, cardiovascular disease, obesity, as well as certain neurological and genetic disorders.

In light of increasingly high rates of diabetes, heart disease and obesity, popular health discourse in the region has emphasised the emergent Arab genome as the primary etiological basis of major health conditions (see Parkhurst 2014, this issue). Local health authorities focus on programmes looking at genetic susceptibility for certain health concerns. In recent years, the Qatari government has implemented dozens of public awareness campaigns intended to educate Qataris about healthy eating, exercise, and fitness. It has been reported that "more delicate cultural issues", such as family marriage "are being addressed by "higher-ups in society." Community leader and sheikhs are engaged by public health drives to communicate such messages around risk (http://www.theatlantic.com/health/archive/201 I/I I/the-richest-fattest-nation-on-earth-itsnot-the-united-states/248366/). Research, including the mapping of the genome, has been undertaken in order to understand Qatari genetic difference and its impact on health. The basic goal of the QNRF-funded Weill Cornell Medicine- Qatar (WCM-Q) research, as outlined by the lead, Dr. Crystal: "involves trying to understand the structure of the genome of the Qataris and put that in context with the environment to see how we can use that information to help the population in terms of general health, understanding disease, developing appropriate therapies" (QNRF 20I5). Such research exemplifies the next phase of genetic research and involves localized research to discover patterns in heritage and genetic susceptibilities to disease. In Qatar this has focused on the local Qatari population in order to map ancestral background and isolate areas of the Qatari genome that could potentially allow prediction and intervention. Rodriguez-Flores et al 2014 outlined three 
categories of the Qatari local population: Q1 Bedouins, Q2 Persian or South Asian mixture and Q3 African-derived Qataris. This research team plans to build upon this knowledge to study the responses of the different genetic populations to the same environmental stressors. As more studies into the local population take shape, researchers will also be able to isolate more monogenetic diseases prevalent in Qatar, such as thalassemia. Such research aims to understand the differences between the Qatari populations and other populations in order to learn why Qataris are more susceptible to certain disorders.

A number of projects have been developed to further Qatar's vision. In 2013 The Qatar Genome project was launched in order to identify diseases and illness "in order to have personalised treatment and medications for such diseases", according to HMC Managing Director Hanan al-Kuwari (Gulf Times 20I3). The SIDRA Medical and Research Centre is to be an "ultramodern, all-digital academic medical center which will set new standards in patient care for women and children in Qatar, the Gulf region and internationally" (http://www.sidra.org) and "help Qatar grow as a hub for genetic medicine":

[It] will house a first-of-its-kind facility, the High-Throughput Genomics Center, to undertake population studies and genetic sequencing for the MENA region. The facility will provide Qatar and the region access to the latest technology to help advance genetic mapping projects. The facility's early phase of development is the creation of the Arab consensus genome, which will allow for a deeper understanding of genetic variants that contribute to the health of the Arab population.... The initial focus of the facility will cater primarily to high-end applications, including human whole genome sequencing for rare genetic diseases and population studies.... Genome sequencing and population studies are an exciting new field of research, enabling scientists to create truly personalized care based on an individual's own genetic makeup.

WCM-Q is conducting research involving the sequencing of I,000 Qataris representing " 0.3 percent of the whole Qatari population" (QNRF 20I3). However, this does not include the entirety of the population, but only Qatari nationals. This is particularly exclusive given the way that nationality is conferred: through the male Qatari line. Hence, offspring of Qatari women are not considered nationals if their father is non-Qatari.

The genomic revolution has furnished potent resources for the expression of nationhood (Atkins and Glasner 2007). The research projects outlined above resonate with the nation's overall research strategy, which is tied in to the Qatar National Vision (QNV) 2030, which "is based on the guiding principles of Qatar's Permanent Constitution. It is the primary catalyst driving change and growth across Qatar [and] reflects the aspirations of the Qatari people and the resolve of its leadership" (General Secretariat For Development Planning 2008). One must remember that Qataris make up $12 \%$ of the country's population and the rest are migrant workers, many of whom have different experiences of health and access to services and opportunities as outlined by such mandates. Such research raises questions about who benefits from investment in genomics. Are migrant workers, for example, able to access genetic interventions? Are they potential research participants in genetic research? Gardner et al (2013) found that $7 \%$ of the foreign workers reported that they did not have a QID (residence permit). However, what is particularly relevant for the discussion here is that a much larger percentage (56\%) of the workers lacked a government-mandated "health card" (Gardner et al 20I3). This document is required for accessing health care in the state's expansive public health system. Thus, over half of the foreign residents are unable to access basic state funded health care, let alone genetic interventions.

Genetics provides a powerful idiom for the expression of individual and collective identity. QNRF has funded genome-sequencing projects and is independently pursuing the whole 
genome sequencing of 300,000 Qatari nationals, representing almost the entire Qatari population (Al Mulla 20l4; http://www.gulf-times.com/qatar/l78/details/374345/qatarlaunches-genome-project). The nation appears in discussions around genomic patrimony and sovereignity (Rabinow 1999; Benjamin 2009). Genomic researchers and proponents of genome projects in Mexico and India 'strategically calibrate' contrasting modes of groupmaking (Benjamin 2009). The Qatari project resonates with Rabinow's (1999) interpretation of the reality of "French DNA" through his account of the undoing of the commercial exchange of DNA from French families to a US biotech company. The French government considered DNA samples to be part of the collective patrimony and therefore not appropriate as items of commerce: Rabinow, thus, contrasts this with the US system where body parts (i.e blood) can be sold. An individual's body and body parts are seen as part of the French patrimony. The economics of biovalue mean that DNA may be regarded as a national resource, as well as a repository of national characteristics (Atkinson \& Glasner 2007). The rhetoric of biological inheritance and relatedness is not new and has long provided a vocab of nationality, nobility and purity (Atkison \& Glasner 2007). The intersection of national and biological identity has been documented in many contexts and is particularly true of Qatar.

Saudi Arabia has initiated the sequencing of about 100,000 Arabs from around the Kingdom (http://rc.kfshrc.edu.sa/sgp/). The ambitious remit of these programmes resonates with the calls to widen programmes of genetic research to global health care arenas outside Western Europe and North America and to include genotype information from 'minority populations' and 'other ethnic groups' (see Bustamante et al 20ll). The need to include genotype information from broader and more diverse groups is desired mainly so that those most in need will be included in research and subsequent interventions. However, in Qatar the aim is to provide specific information related to Qatari bodies and diseases and, thus, seems less about underserved populations and more about national relevance. Concern has been raised that data generated from such genome projects will be unconnected because of its politically driven nature. As Kuwaiti based geneticist Al-Mulla suggests, genome sequencing "is viewed only as a national endeavor rather than a humanitarian triumph or necessity" and argues "locking genomes... contradicts the goal of genomic research, namely that the benefits be shared globally" (2014:133). It is likely that such research will produce findings that will help other populations, but this may be a side effect rather than the central aim. For example, Crystal, the lead of the WCM-Q genetic mapping project noted that the mapping and analysis of Qatari genomes has provided unexpected insight into a genetic variation that affects other populations all over the world. One study focuses on a variation gene "ApoE", which makes carriers susceptible to having increased levels of unhealthy fats called triglycerides in their blood. Considered rare, the variant was far more common in those with sub-Saharan African extraction; its presence is associated with disorders such as heart disease, type-2 diabetes and stroke (Abou Ziki et al 20I4). The research included $1266 \mathrm{New}$ York African-Americans and found that four per cent carried the RI45C variant and, thus, Crystal points out, has implications for African derived populations throughout the world: "it was extremely gratifying for us to make a discovery in Qatar that provided insight into the health of people in New York" (QNRF 20I5).

Whilst the Qatari government has emphasised genetics research and medicine as keys to creating a healthier society, the particularities of the Qatari context have attracted global genetic research initiatives. The generous funding programmes, emphasis on research and development, and possibilities for international collaborations have enabled an impressive research landscape. The genetic singularity of the Qatari population, high rates of consanguinity and the high prevalence of certain conditions both highlights the need and offers the opportunity to study the genetics of recessive single-gene disorders (Marincola \& Sheikh 2012). Research into the relationship between consanguinity and the severity of multi-genic complex diseases of adulthood could also be investigated in Qataris better than 
in most populations worldwide: for example, research into the high prevalence of type II diabetes in Qataris and the connections between socio-economical factors, endogamy and/ or consanguinity could be disentangled (Marincola \& Sheikh 20I2). Indeed, genetics studies related to diabetes and obesity are currently being conducted at WCM-Q as well as QBRI.

\section{Genetics and genomics: public understandings and negotiations}

Genetic discourses have a high profile in Qatar through local media reports, public health initiatives and the research landscape. Seen as the key to improving the health of Qataris they are part of a state political drive to be seen as a harbinger of cutting edge research and knowledge: to be a modern and "cosmopolitan" country. I now explore how this vision of Qatar, particularly with its harnessing of global discourses on genetics, is experienced and interpreted by Qataris themselves. In particular, I explore the discrepancy between scientific implications and lay interpretations of inheritance. Central to this is a process of negotiation and containment in order to re-establish the balance between tradition and modernism that is at the heart of contemporary Qatari social life. Thus, the role of genetics as part of the Qatari state's mission to become "modern" can be at odds with the way that Qataris themselves understand and incorporate genetic knowledge into their lives.

Despite years of public dissemination of genomic knowledge in the region, its commonality and widespread acceptance; the rates of diabetes, obesity and heart disease continue to rise. Many have commented about the sudden, severe problems of obesity and diabetes among wealthy citizens in the Gulf over the past decades. The link is made between these condition and modernity: these are medical conditions that were almost completely non-existent before the oil boom:

These observers seem to feel that the diabetes, an inability of the body to absorb glucose because of lack of insulin, is analogous to a deeper intellectual and philosophical problem existing in the social fabric of Qatar: the inability to digest and process the meaning and possible negative consequences of modern change (Fromhertz 2012).

The suggestion is the high rates of diabetes and obesity are related to an inability to digest change. Gulf Arabs themselves often see these as conditions of modernity and many do not appear willing to consider personal habits as responsible for their wellbeing (Parkhurst 2014; this issue). Lay observations about the rise of such "new" diseases resonate with theoretical observations of risk as an aspect of modernity (Beck 1992, Giddens 199I, Caplan 2000) and with lay observations by, for example, British Pakistanis that risk is greater in modern societies (Shaw and Hurst 2008). Parkhurst observes that Gulf Arabs often cite the presupposed Arab predispositions to Type 2 diabetes as the ultimate issue in discussions of treatment and lifestyle choices:

These habits are a form of personal violence embedded in many Emirati lifestyles. This type of violence is internal, and genes, as a category of fate are inducted into indigenous cosmology, are perfect foreign agents. They are embedded in the body, but not part of familial kinship... They are perhaps perceived as sacred when they are categories of fate, or agents of Allah, and they are mundane as agents of disease. They might cause disease, but they are also thought to be at the heart of being Arab (20I4:193).

Qatar has reacted to modernization uniquely: the '"heroic' in Qatar is associated not with the 'now', a now dominated and built by migrant labour, but with what is 'behind it'- a past reconstructed and reconstituted into nationalized historical moments" (Fromhertz 20I2:15). The government has perpetuated neo-traditional myths of culture and authenticity: 
Qataris have instead maintained tradition or at the very least, constructed newtraditional notions of identity. Shielded from the most ravishing consequences of modernization by enormous wealth and by a dependence on a massive expatriate community, Qataris can maintain a bubble of culture and internalized authenticity. It is no mere fashion that leads all Qatari men to wear their traditional thob at all times in Qatar, moving through Western spaces and even influences while maintaining lineage and family as the primary determinant of destiny (2012:13).

\section{Consanguinity: containment and tradition}

Despite the high profile of genetic discourses and particularly public health messages about the risks of family marriage, consanguinity is on the increase in Qatar. The global spread of biomedicine has brought with it a globalizing discourse of risk accompanying the practice. Attitudes of Western cultures and medical professionals toward consanguinity are often negative, ostensibly because of the impact on health (see Shiloh et al. 1995; Bittles and Makov 1988). As Shiloh et al (1995) suggests such notions have "penetrated even in societies where this kind of marriage is common, and have been integrated into more general attitudes and beliefs about consanguinity" ( $\mathrm{p} / 30 \mathrm{I})$. Such is the case in Qatar where despite being a dominant marriage pattern, the negative discourse of risk has been integrated into public discourse, linked, in part, to the country's continuing emphasis on modernization.

As Bittles (2012:1) outlines, "it has become virtually impossible to persuade members of the general public that inbreeding, and by extension marriage between biological relatives, can be anything other than harmful.' This is despite the fact that there is growing evidence that the deleterious effects of consanguinity are exaggerated (i.e. see Shiloh 1995). Shaw (2009 49) states:

Public perceptions of risk are not neutral: a 'climate of disapproval grounds the belief that certain deeds are dangerous' (Douglas 1992:27). Moreover, in the current political climate of Muslim/non-Muslim relations in contemporary Europe, the biological risk of cousin marriage provides 'scientific' grounds for disapproval of a marriage practice... for persisting in risky behavior, resisting cultural conformity.

By actively drawing in these discourses, there is in Qatar a focus on the dangers of consanguineous marriage that is communicated through public health drives. Mandatory premarital screening programme for all couples intending to marry are one of the main ways that Qatari citizens confront genetics. Across the Middle Eastern region, the rates of consanguinity range in most societies from $20 \%$ to $55 \%$ of all marital unions (Bittles et al 199I; Bittles 2012). However, unlike in many parts of the world (Lebanon, Saudi Arabia, Kuwait, Jordan, Israeli Arab communities and the Palestinian territories) the practice is on the increase, as it also is in the United Arab Emirates (UAE), Yemen, Iran (Bittles 201 I:62). The increasing rates of consanguinity contradict the assumption that modernization will "inevitably reduce the incidence of consanguinity" (Jurdi\&Saxena 2003:2; in Qatar see Harkness 20I4; Al-Ghanim 20I0)). A recent study found that 54\% of Qatari marriages are consanguineous with first cousin unions being the most common: $34.8 \%$ of all marriages and $64.4 \%$ of all consanguineous unions (Bener \& Hussain 2006).

Consanguineous marriage is common not only in the Middle East, but also in South Asia, North Africa and parts of Southern Europe. Shaw (2009), found a similar increasing trend amongst British Pakistanis over the past decade, contrary to expectations. Rozario's (2013) study of British Bangladeshi Muslims found that, despite negative views of cousin marriage amongst health care professionals, respondents saw the practice as a way to retain a "purity of blood". The "assumption that the decision remains in Allah's hands makes it possible for people to go ahead with cousin marriages despite being perhaps at some level aware of the risks" (Rozario 2013:20I). Research from a variety of cultural contexts has revealed that lay 
and public health/media discourses about genetic risk and cousin marriage do not always correspond (Shaw 2009). Genetic risk was seen as irrelevant and thus, a "differently constituted perception of risk" was present (Shaw 2009:3).

Scholars have shown that encounters with genetics alter social life and understandings in fundamental ways in the Middle East (i.e. Panter-Brick 199I, Raz 2005, Beaudevin 2013). Parkhurst (20I4) shows the robustness of UAE native knowledge system: "Local systems of cosmology, kinship, and fate... all have their own language in which biology must be maneuvered" (p.167). In discussions with my interlocutors, genetics remained entrenched in the language of disease, illness and disability, resonating with Parkhurst's findings: "While there exists a robust local knowledge of the mechanisms of inheritance and kinship, genes as biological entities are not part of, and not associated with this inheritance and kinship.... They are widely known to be carriers of disease, but are not often understood to contain the essence of, or the benign traits of a person" (2014:188).

Individual Qataris are still grouped according to lineage: one's qabila: one's extended "tribe" or family, remains the fundamental determinant of an individual Qataris social position and future (Fromherz 2012:7). Wealth has re-inforced certain aspects of history and lineage: families now have the opportunity to live in large family compounds with their own mosque (Fromherz 2012), emphasizing family allegiances. Fromherz' discussion of the spatial arrangements of buildings is taken further in Gardner's (2013) account of Doha itself. An anthropologist who has conducted research in Qatar, Gardner makes use of Dresch's discussion of the integral feature of Gulf societies as the accommodation of "foreign matter" and applies it to Doha's urban spatial discourse. The urban spatial discourse involves spatialization and enclaving of globalization and neoliberal flows:

The compartmentalization of foreign matter -people, practices, and ideas- is fundamentally an assertion of cultural sovereignty over the domain punctuated by these exceptional spaces. Put another way, this urban spatial discourse is an assertion of Qatari cultural sovereignty over the cosmopolitan and transnational heterogeneity so essential to the developmental goals of state and citizenry. This urban spatial discourse reflects the relationship between a people and the foreign matter they both host and depend upon. This relationship is woven into the shape of the city (Gardner 20I3)

There is a similar containment of genetic discourse as it relates to risk. Skepticism reflects a rejection of a dominant discourse of genetic risk that stigmatizes cousin marriages (Shaw and Hurst 2008). Such a process resonates with the containment of foreign influences and bodies in the urban space of Doha and the notion of cosmopolitanism found in Education City. Thus, in the case of Qatar, modernization has provided opportunities for containment of the global flows that accompany it.

\section{Traditional modernists}

One of the ways that bodies, spaces, ideas, practices and discourses are contained and altered is through an emphasis on tradition. A constant balancing between the forces of modernization and tradition is felt acutely in Qatar: it pervades most aspects of social life. Qatari identities mix modern (i.e., Western) and cosmopolitan (i.e., global) whilst adhering to local customs and traditions. The distinct amalgam of customary and contemporary is a crucial element of most projects in Qatar, from higher education to museums to sports (Harkness \& Khaled 20l4). Rajakumar (2014) argues the embodiment of this delicate balancing can be seen in the form of Sheikha Moza, the second wife of the former and mother of the current Emir. The Sheikha has played a key public role and was the driving force behind a large number of initiatives, including the development of Education City. She espouses a "plural, liberal interpretation of Islam, which focuses on the religion's emphasis 
on education, the role of the individual in society, and the betterment of the world" (Rajakumar 2014: 127).

Positioning herself as a "modern traditionalist," the Sheikah's recent speeches have increasingly emphasised the blend of Arab identity, modern pragmatism, and importing the best educational models to make Qatar a hub for innovation in the Arab World (Rakakumar 2014:128). This emphasis certainly resonated with what many of us working in/ on Qatar were experiencing: a re-alignment in such a way to de-emphasise the role of foreign experts, with purposeful alignment between Qatar, Arab identity and an emphasis on Arab intellectuals (Rajakumar 2014:138). This seems to be part of a general re-balancing in favour of tradition and Arab culture in the face of increased development and foreign influences.

Historical data demonstrate that social changes in the Middle East are sometimes met with conservative reactions that include the enactment of traditional policies and cultural expectations (Harkness \& Khaled 20l4). Scholars working in Qatar have shown that tribal "tradition" is often increased not decreased with wealth (see Fromhertz 2012, Gardner 2013, Al-Ghanim 2010), particularly in relation to social roles, marriage practices and adherence to traditional dress. For example, the increased use of the hijab in the wake of escalating rates of female employment, education, and athleticism in the region (Jawad, AlSinani, \& Benn, 20II). Thus, family marriage may be part of this negotiation of the traditional and modern.

The continued and increasing popularity of consanguineous marriage may reflect a desire to moderate modernising trends by preserving traditions and customs. Abbasi-Shavazi et al (2008) explain the increased rates of consanguinity in Iran as "cultural maintenance... in the persistence of traditional behaviour despite the forces of modernization" (p.917). In a quickly developing nation such as Qatar, the benefit of the effective transmission of culture could create social stability, which in a period of change could have enormous benefits (Sandridge et al. 20l0). The potential advantages attributed to family marriage include: greater autonomy for women, benefits such as familial unity, decreased pressures on the bride in her new home, a stronger marital bond with less risk of divorce, greater compatibility of the bride with her husband's family, property retention and effective transmission of the culture from generation to generation (Sandridge 2010; Barth 1953; Khlat et al. 1986; Bittles 1994; Ottenheimer 1996). Interlocutors spoke of the importance of familiarity with customs and traditions when looking for a potential spouse for their children. They hinted at notions of purity and authenticity: familiar customs and practices would allow women to effectively impart them to future generations. Indeed, the importance of this is central to Qatari society, as outlined in the Qatar Development Strategy:

The family is the basis of Qatari society... Qatar's strong Arab and Islamic identity pervades all aspects of family life and continues to inform the family structure, but changes brought on by external pressures and internal evolution are changing family dynamics.... Women are central to this positive, evolving nature of the Qatari family. Even as they maintain an adherence to valuable traditions, women are adapting to the impacts of modernization. They exemplify the new opportunities available to all Qataris as a result of the country's rapid economic growth and social transition. (p.17).

We have argued that whilst aware of the discourse of risk and close marriage, Qataris negotiated with other forms of risk, such as the potential dangers of marrying a daughter to "strangers" (Kilshaw et al 2015). Thus, marriage in the family mean the woman would be more comfortable, have closer ties to her nascent family and would share cultural traditions in order to effectively impart to children. Our interlocutors were often unwilling to accept the idea of disease as inherited, stating that not all members of the family were affected. 
Panter-Brick (1991) similarly found that unless family history made an inheritance factor obvious, Saudi participants were unlikely to see the condition as genetic and thought genetic illness should affect all children and should appear soon after birth. Whilst aware of the discourse of consanguinity risk, interlocutors seemed unsure of its reality and used anecdotal evidence to support uncertainty. Qatari interlocutors cited examples where cousin couples had many healthy children or referred to families where offspring had disabilities despite the parents being unrelated (see also Panter-Brick 1991). Wadha, a 33year-old mother of nine explained that people often suggest that her son's disability was due to 'inheritance', but she refers to it as 'fate'

One of my sisters is married to my father's sister's son and all of her children are normal. Many cases of marrying within the family in our family and nothing happened.

When discussing whether or not they thought their child's disability was genetic many would respond saying: "there are no other cases in the family" or "there is no one in the family like [her]." Amna, who offered such an explanation further expanded, saying it was common practice within her family and did not increase risk:

No, I don't think so. I think anything is destined to happen whether they are cousins or not.

Aisha, the mother of a daughter with autism, believed her daughter's condition to be caused by her emotional state whilst pregnant:

I was upset because of problems between her father and I. I was very upset. We had many daily problems. When I was pregnant, I was very stressed and I was always feeling down. It was [the] probable cause of Maryam's condition.

In interviews, respondents often saw the benefits of close marriage as outweighing potential risks (Kilshaw et al 20I5). Although familiar with the discourse of genetics, participants were ambivalent about genetic risk and pointed to other possible causes. Panter-Brick's (1991) research found that despite an awareness of genetic risk, participants often accounted for illness and disability through explanation such as: 'evil eye', 'God's will' and illness or upset during pregnancy. In particular, in Qatar a woman's physical and emotional state during pregnancy took importance over other forms of explanation. A woman's emotional state would also affect the baby's temperament. In the UAE Parkhurst (2014) found traits mainly coming from the father, with others are "picked up" or absorbed from the mother in utero. Similarly, in the Qatar the father is seen as providing the dominant template for traits, and the mother as "influencing". Indeed, some suggested that all genetic material comes from fathers. Qatari models of inheritance, including social and biological, which are seen as tracking primarily through men have parallels outside this region. The Alawi of Southeastern Turkey have notions of inheritance that stress patrilineaty based on a concept of the differential transmission of male and female blood / genes (Prager 2015). Shaw and Hurst (2008) identified a "cultural blueprint" amongst British Pakistanis that appears to prioritize inheritance through men. Men are seen as the perpetrators of lineage or identity, with a father's genetic contribution to a child, through the substance of blood, stronger than that of the mother's because semen is concentrated in blood (Shaw 2015).

A mother's influence is felt in utero but also through her role in raising children including breastfeeding: women were told not to breastfeed when angry or sad so as not to transmit to the baby. A Qatari pregnant woman is supposed to be calm and relatively tranquil. She is to protect her unborn child from outside risks and also from stress, anxiety and upset (Kilshaw et al, 2016), reflecting notions of maternal influence. Pregnant women, women who 
had recently miscarried and family members of a disabled child all spoke about the importance of a woman's emotional, psychological and physical state when pregnant. Such discussions appeared to take precedence when people were making sense of problems and linked to cultural systems of blame and risk. Thus, despite the fact that everyday notions of inheritance emphasised the man's contribution, problems in pregnancy or with a child are often attributed to maternal influences. Such findings have been found in other contexts: Shaw and Hurst (2008) found that their interlocutors reported that problems in a pregnancy or a child were blamed on the mother's actions during pregnancy (see also Rozario 2013), particularly in relation to attracting jinn as the result of some bad or careless behaviour (Shaw and Hurst 2008; Shaw 2000:209-212). Ultimately, God determines a person's fate, including in granting health, illness or pregnancy loss. Personal or religious beliefs and local understandings of illness causality may mean that genetic problems are viewed as matters of fate, destiny or God's will, as among Muslims in Saudi Arabia (Panter-Brick 199I).

\section{Conclusions}

Genetic discourses have taken a predominant role in approaches to combating a number of conditions that affect Qataris. Qataris have increased susceptibility to some diseases and the state's focus on genetics shows its dedication to improving the lives of its citizens and desire to strengthen the nation. Whilst the incentive behind the development of genomic medicine is to improve the nation's health, this currently rests on a narrow understanding of nationhood. This is particularly interesting in a climate where there are increasing calls to widen the scope of genomics to include a wider diversity of people and to harness such knowledge and information for those most in need.

This campaign should be seen in relation to the way genetic discourse is accommodated and understood by in Qatar and with an understanding of local configurations through which genetics has been absorbed as part of the "Qatarisation" process. I have pointed towards the multiplicity of discourses where both the global and the local participate in constituting the meaning of genetics, relevance and scope in the Qatar context. The drive is also part of the nation's positioning itself as a modern, leading and cutting edge entity in regards to research, education, and health care. However, whilst the state is eager to incorporate the modern and continue to develop, there is a desire to balance this with an emphasis on Qatari and Arabic tradition. Thus, there is a constant shifting, balancing, re-positioning and re-inventing as the country and its people negotiate global interactions and influences. This paper has described the unevenness of change in Qatar. There have been dramatic lifestyle changes in some areas but not others. Family marriage is one of the main platforms where one can see the way modern, cosmopolitan and tradition are negotiated. Indeed consanguinity has been shown to be at the heart of tensions and negotiations of modernity and tradition in a variety of global contexts (i.e. Shaw 2015; Prager 2015; Shaw and Raz 2015). This paper contributes to the scant literature on the impacts of genetic discourse on genetic risk in consanguineous marriage in diverse global settings (Shaw and Raz 2015) through a focus on the Qatari context. I have aimed to reveal some of the ironies and contradictions in the focus on genomics as a key area in the quest of modernity because inheritance is simultaneously the key to tradition. Tradition itself is central to the process of containment of outside forces and undesirable change. 


\section{REFERENCES}

Abbasi-Shavazi, M. J., McDonald, P., \& Hosseini- Chavoshi, M. (2008). Modernization or cultural maintenance: The practice of consanguineous marriage in Iran. Journal of Biosocial Science, 40, 911-933.

Abou Ziki, M. Strulovici-Barel, Y., Hackett, N., Rodriguez-Flores, J. Mezey, J., Salit, J., Radisch, S. Hollmann, C., Couchane, L., Malek, J. Zirie, M., Jayyuosi, A., Gotto, A., and R. Crystal. Prevalence of the ApoE Argl45Cys Dyslipidemia At-risk Polymorphism in African-derived Populations. Am J Cardiol. 20 I4. I I3(2):302-308

Al-Ghanim, K. 2010. "Consanguineous Marriage in Qatar: Marriage Selection in a Society in Transition." World Academic Union (World Academic Press), Proceedings of 2010 International Conference on Humanities, Historical, and Social Sciences (CHHSS 20I0) Singapore, 26-28 February, 2010.

Al Mullah, F. 20 I4. Commentary. Applied \& Translational Genomics. 3(4):I32-I33

Atkinson, P. and P. Glasner 2007. Introduction Atkinson, P., Glasner. P. and Greenslade, H. (eds). 2007. New Genetics, New Identities. London: Routledge.

Barth, F. 1953. Principles of social organization in southern Kurdistan. Universitetets Ethnografiske Museum Bulletin No. 7 Brodrene Jorgensen A/S-Boktrykkeri, Oslo.

Beaudevin, C. 2013. "Old Diseases and Contemporary Crisis. Inherited Blood Disorders in the Sultanate of Oman." Anthropology and Medicine 20: 175_189.

Beck, U. 1992. Risk Society. London: Sage.

Bener, A. \& Alali, K.A. 2006a. Consanguineous marriage in a newly developed country: the Qatari population. Journal of Biosocial Science 38, 239-246.

Bener, A. and R. Hussain. 2006b. Consanguineous unions and child health in the State of Qatar. Pediatric and Perinatal-Epidemiology 20: 372-378.

Bener A, Hussain R, Teebi AS. 2007. Consanguineous marriages and their effects on common adult diseases: studies from an endogamous population. Med Princ Pract. 16(4):262- 7.

Benjamin, R. (2009) A lab of their own: Genomic sovereignty as postcolonial science policy. Policy and Society 28(4): 34I-355.

Bittles A. 20II. The global prevalence of consanguinity. http://www.consang.net accessed October 2013.

Bittles, A.H. 20I2. Consanguinity in Context

Bittles, A. H., 1994. The role and significance of consanguinity as a demographic variable. Population and Development Review 20(3), 56I-584.

Bittles, A. H., Mason, W. M. Greene, J. and Rao N.A. 199I. Reproductive behavior and health in consanguineous marriages. Science 252789. 
Bittles, $\mathrm{AH}$ and Makov. E. 1988. Inbreeding in human populations: an assessment of costs. In Human Mating Patterns (edited by Mascie-Taylor, CGN and Boyce, AJpp. I53-I67.

Camridge: Cambridge University Press.

Bustamante, C., De La Vega, F., E. Burchard. 20I I. Genomics for the World. Nature 475: 163-165.

Caplan, P. (Ed.). (2000). Risk revisited. London: Pluto Press.

Cooke, M. 2014. Tribal Modern: Branding New Nations in the Arab Gulf. Berkeley: University of California Press.

Douglas, M. 1992. Risk and Blame: Essays in cultural theory. London: Routledge. 1966. Purity and Danger: An analysis of the concepts of pollution and taboo. London:Routledge

Fromherz, A. 2012. Qatar: A modern history. London: I.B. Tauris.

Gardner, A. et al 2013. Journal of Arabian Studies 3(I):I-I7

Gardner, A November 92013 Jadillya. http://www.jadaliyya.com/pages/index//5022/thetransforming-landscape-of-doha_an-essay-on-urb. Last accessed March 42016.

Giddens, A. 1991. Modernity and self identity. Cambridge: Polity Press.

Gulf times. Article by Olayiwola, N. 2013, Dec II.

Harkness, \& Khaled, R. 20I4. Modern Traditionalism: Consanguineous Marriage in Qatar. Journal of Marriage and Family73 (3): 587-603.

Inhorn, M. 2009. Reproductive disruptions and assisted reproductive technologies in the Muslim World. In Inhorn, M (ed) Reproductive disruptions: Gender, technology, and biopolitics in the new millennium. Oxford: Berghahn Books. Pp. I83-199.

Jawad, H., Al-Sinani, Y., \& Benn, T. (20I I). Islam, women, and sport. In T. Been, G. Pfister, \& H. Jawad (Eds.), Muslim women and sport (pp. 25-40). London: Routledge.

Kane, T. 2013. Higher Education in Qatar: does a US medical school break the baroque arsenal? In Donn, G and Y. Al Manthi (eds) Education in the Broader Middle East: Borrowing a baroque arsenal. Didcot, Oxford: Symosium Books. pp.85-105

Khlat, M., Halabi, S, Khudr, A. \& Der Kaloustian, V.M. 1986. Perceptions of consanguineous marriages and their genetic effects among a sample of couples from Beirut. American Journal of Medical Genetics 25, 299-306

Kilshaw, S., T. Al Raisi, F. Alshaban. 20I5. Arranging marriage; negotiating risk: Genetics and society in Qatar. Anthropology \& Medicine 22(I): 98-II3

Kilshaw, S., Miller, D. Al Tamimi, H., El-Taher, F., Mohsen, M., Omar, N., Major, S. and K. Sole. Calm vessels: Cultural expectations of Pregnant Women in Qatar. Anthropology of the Middle East I I (2) (20 I6)

Marincola, F. M. and J. I Sheikh. A road map to Translational Medicine in Qatar and a model for the world. J Transl Med. 20I2; I0: 177. 
Ottenheimer, M. 1996. Forbidden relatives. The American myth of cousin marriage. University of Illinois Press, Urbana and Chicago.

Panter-Brick, C. 1991. Parental Responses to Consanguinity and Genetic Disease in Saudi Arabia. Social Science \& Medicine 33: |295-1302.

Parkhurst, A. 2014. "Genes and Djinn: Identity and Anxiety in Southeast Arabia." PhD Dissertation, Department of Anthropology, UCL.

Prager, L. 2015. Dangerous Lisasons: Modern Biomedical Discourses and changing practices of cousin marriage in southeastern turkey.

QNRF. 2013. Researchers making headway on decoding the Qatari genome. QNRF Newsletter (13). http://qnrfnewsletter.org/issue I3/funded_research I.php

QNRF "Success stories". 2015. Researchers making headway on decoding the Qatari Genome. November 2 http://www.qnrf.org/en-us/Outcomes/SuccessStories/ArtMID/654/ArticleID/79I/Researchers-making-headway-on-decoding-the-Qatarigenome

Qatar National Vision 2030. July 2008 Doha: General Secretariat for Development Planning Doha, Qatar www.planning.gov.qa

Rabinow, P. 1999. French DNA, Trouble in Purgatory. Chicago: University of Chicago Press.

Rajakumar, M. 2014. Assessing the Rhetoric of Sheikha Moza: Mistress of Ethos. In Global Women Leaders: Studies in Feminist Political Rhetoric. Edited by M. Lockhart, K. Mollick. London. Lexington Books.

Raz, A. 2005. The gene and the genie: Tradition, Medicalization and genetic counseling in a Bedouin Community in Israel. Durham, North Carolina: Carolina Academic Press.

Rodriguez-Flores, J. L., Khalid Fakhro, Neil R. Hackett, Jacqueline Salit, Jennifer Fuller, Francisco Agosto-Perez, Maey Gharbiah, Joel A. Malek, Mahmoud Zirie, Amin Jayyousi, Ramin Badii, Ajayeb Al-Nabet Al-Marri, Lotfi Chouchane, Dora J. Stadler, Jason G. Mezey, Ronald G. Crystal. 2014. Exome Sequencing Identifies Potential Risk Variants for Mendelian Disorders at High Prevalence in Qatar. Human Mutation. Volume 35, Issue I: I05-I 16

Rozario, S. 2013 Genetic disorders and Islamic identity among British Bangladeshis. Durham, NC: Carolina Academic Press.

Sandridge, A., J. Takeddin, E Al Kaabi, Y Francis. (2010) Consanguinity in Qatar: Knowledge, attitude and practice in a population born between 1946 and 1991. J. Biosoc. Sci 42: 59-82

Shaw, A 2015 British Pakistani cousin marriages and negotiation of reproductive risk. Cousin Marriage: Between Tradition, Genetic Risk and Cultural Change. A. Shaw and A. Raz (eds.) pp I I3129

Shaw, A. 2000. Kinship and Continuity: Pakistani families in Britain. Amsterdam, London: Routledge. 
Shaw, A. and A. Raz. 2015 Introduction. In Cousin Marriage: Between Tradition, Genetic Risk and Cultural Change. A. Shaw and A. Raz (eds.). ppl-32.

Shaw, A. 2009. Negotiating Risk: British Pakistani Experiences of Genetics. Oxford: Berghahn Books.

Shaw, A. and JA Hurst. 2009. 'I don't see any point in telling them': attitudes to sharing genetic information in the family and carrier testing of relatives among British Pakistani adults referred to a genetics clinic. Ethn Health. 2009. Apr 14(2):205-24.

Shaw, A. and JA Hurst 2008, "What is this genetics, anyway?" Journal of Genetic Counselling I7, (4) 373-382.

Shiloh, S. H. Reznik, M Bat-Miriam-Katznelson, and B. Goldman. 1995. Pre-marital genetic counseling to consanguineous couples: attitudes, beliefs and decisions among counseled, non counseled and unrelated couples in Israel. Social Science and Medicine Vol 4I, No. 9: I30I1310. 